\title{
The association of uric acid with metabolic syndrome among Kuwaiti adolescents
}

\author{
Abdulwahab Naser Al-Isa ${ }^{1^{*}}$, Abayomi O. Akanji $^{2}$ \\ ${ }^{1}$ Department of Community Medicine \& Behavioural Sciences, Faculty of Medicine, Kuwait University, Kuwait City, Kuwait; \\ *Corresponding Author: alisa@hsc.edu.kw \\ ${ }^{2}$ Department of Pathology, Faculty of Medicine, Kuwait University, Kuwait City, Kuwait
}

Received 27 February 2013; revised 12 April 2013; accepted 15 May 2013

Copyright (C) 2013 Abdulwahab Naser Al-Isa, Abayomi O. Akanji. This is an open access article distributed under the Creative Commons Attribution License, which permits unrestricted use, distribution, and reproduction in any medium, provided the original work is properly cited.

\begin{abstract}
Background: The association between uric acid (UA) with metabolic syndrome (MS) has been researched more in adults than in adolescents. In fact, this association is not completely understood among adolescents. Objectives: The purpose of this study was to explore the association between UA with MS. Methods: A crosssectional sample of 742 Kuwaiti adolescents (303 males and 439 females) who were apparently healthy, chosen from randomly selected schools were used for the study; four intermediate (two males and two females) and four secondary (two males and two females) schools. Results: The results of the study showed the UA level was highly associated with MS, especially among males. UA was significantly associated with each of the six parameters of MS. Conclusions: The level of uric acid among the adolescent was high and it was significantly associated with MS and gender. Dietary interventions are necessary to reduce UA and the parameters of MS among the adolescents.
\end{abstract}

Keywords: Kuwaiti; Adolescents; Metabolic

Syndrome (MS); Uric Acid (UA); Arab

\section{INTRODUCTION}

It has been suggested by several studies that UA constitutes a risk factor for the development of cardiovascular disease [1-3]. There is a controversy over the contribution of UA to atherosclerotic vascular disease [4]. The association of UA with MS in adolescents has yet to be fully understood unless studies were to be conducted on adolescents who are free of chronic diseases and rule out that the association is secondary to such diseases [5]. It has been argued that the association between UA and atherosclerotic vascular disease is possibly because of an indirect relationship between hyperuricemia with cardiovascular risk factors or the aggregation of some risk factors that are both metabolic and hemodynamic, which are designated as MS [6,7]. Studies on adults have shown that vascular smooth muscle proliferation is stimulated by UA and, as a consequence, this stimulation induces endothelial dysfunction. Moreover, UA tends to decrease the production of endothelial nitric oxide and eventually leads to endothelial dysfunction and insulin resistance $[8,9]$. Once vascular inflammation and artery damage is induced by UA, the risk of atherosclerosis is increased. The relationship between UA, MS, and carotid atherosclerosis have been explored in adults but little is known of this association among adolescents, which necessitate the exploration of these associations among adolescents [10-14]. The association of UA with some MS parameters has been suggested in adults [15]. The scope of these studies on this association is limited in adults let alone adolescents [16]. Therefore, the purpose of this study was to explore the association of UA with MS among Kuwaiti adolescents.

\section{METHODS}

To assess the association between UA with MS. A previous study was conducted on a cross-sectional sample of Kuwaiti adolescents aged $10-19$ years, which was related to the prevalence of MS among the aforementioned group [17]. Ethical approval was taken by the local Ethical Committee, Faculty of Medicine, Kuwait University. The subjects were examined in the morning after at least a 10-hr overnight fast. The fasting blood samples were then collected via venipuncture and kept cooled in an ice box until the separation in a refrigerated 
centrifuge. The resultant plasma and serum samples were stored frozen at $-80^{\circ} \mathrm{C}$, until analysis were performed.

Blood pressures (BP both systolic and diastolic) were measured with a standard gauge mercurial sphygmomanometer after instructing the adolescents to be seated. Waist circumference (WC) was measured by using a measuring tape, midway between the inferior margin of the ribs and the superior border of the iliac crest. The weight was measured inkilograms with the subject wearing light clothes, using Seca digital scale. The height was measured in meters with the subject standing with his back against the wall. The body mass index (BMI) was calculated by dividing the weight in kilograms over the height in meters squared $\left(\mathrm{kg} / \mathrm{m}^{2}\right)$. All the measurements were taken by the same investigator, so as to avoid inter-observer variations. Fasting blood sugar(FBS), lipid profile such as HDL and triglyceride (TG) levels and normal renal function test, in order to estimate serum UA level were performed by an Autoanalyzer techniques, using dedicated reagents and quality control (QC) materials (Beckman DxC Autoanalyzer, Beckman-Coulter Diagnostics, Fullerton, CA, USA). Also, there is no universally accepted threshold to define hyperuricemia in children and adolescents, hence we calculated its prevalence using several thresholds: $>327 \mu \mathrm{mol} / \mathrm{L}(5.5 \mathrm{mg} / \mathrm{dL})$ [4], $\geq 357 \mu \mathrm{mol} / \mathrm{L}(6 \mathrm{mg} / \mathrm{dL})$ [5], and $>416 \mu \mathrm{mol} / \mathrm{L}(7$ $\mathrm{mg} / \mathrm{dL}$ ) $[6,7]$. The final sample included 742 Kuwaiti adolescents, 303males and females 439. The exclusion criteria included those with diabetes mellitus, hypertension, cardiac diseases, renal diseases, epilepsy, subjects receiving medications, and those with broken legs(with cast), for the sake of weight measurements.

\section{STATISTICAL ANALYSIS}

The statistical data was analysed using the SPSS (statistical program for the social sciences) version 17. This included descriptive statistics such as mean, standard deviation and median. The relationship between UA and the six parameters namely, triglyceride, glucose, waist circumference, systolic and diastolic blood pressure and high-density lipoprotein cholesterol were measured by using Pearson's correlation.In addition logistic regression analysis was performed. The statistical significance was defined as $\mathrm{p}<0.05$.

\section{RESULTS}

The sample comprised of 742 individuals, 303 males and 439 females Kuwaiti adolescents. The mean age of our study group was $13.9 \pm 2.4$ years. The mean of serum UA in males was $327.29 \mu \mathrm{mol} / \mathrm{L}$ and in females was $256.5 \mu \mathrm{mol} / \mathrm{L}$. The mean glucose level for males was 5.2 $\mathrm{mmol} / \mathrm{L}$ and females was $5.03 \mathrm{mmol} / \mathrm{L}$. The mean concentration of triglycerides in males was $0.97 \mathrm{mmol} / \mathrm{L}$ and in females was $0.69 \mathrm{mmol} / \mathrm{L}$. The mean concentration of HDL-C in males was $1.07 \mathrm{mmol} / \mathrm{L}$ and in females was $1.23 \mathrm{mmol} / \mathrm{L}$. The mean systolic blood pressure in males was $122.93 \mathrm{mmHg}$ and in females was $121.05 \mathrm{mmHg}$. The mean diastolic BP for males was 80.81 and for females was $81.40 \mathrm{mmHg}$. The waist circumferencein males was $78.56 \mathrm{~cm}$ and in females was $73.76 \mathrm{~cm}$.

Table 1 shows each MS parameters in relation to UA. The study subjects wereclassified into quartiles, according to their serumUA level (UA-1 to UA-4). Data were presented as mean \pm standard deviation (SD), while comparing the four groups. One-way anova was used.

Table 2 summarizes Pearson's correlation coefficient between MS components and serum UA concentration. UA concentration was significantly correlated with WC, BP (both systolic and diastolic) and FBS. UA was negatively correlated with serum HDL. UA concentration was strongly correlated with TG.

Table 3 shows the quantification of the odds ratio (OR) with respect to association of MS with UA in different

Table 1. Demographic, measurements, and MS parameters of four quartiles of UA.

\begin{tabular}{|c|c|c|c|c|c|}
\hline Variable & $\begin{array}{c}\text { UA-1 } \\
(\mathrm{n}=190)\end{array}$ & $\begin{array}{c}\text { UA-2 } \\
(\mathrm{n}=178)\end{array}$ & $\begin{array}{c}\text { UA-3 } \\
(n=191)\end{array}$ & $\begin{array}{c}\text { UA-4 } \\
(n=183)\end{array}$ & $\mathrm{p}$-value \\
\hline & Mean \pm SD & Mean \pm SD & Mean \pm SD & Mean \pm SD & \\
\hline $\begin{array}{c}\text { Age } \\
\text { (years) }\end{array}$ & $13.9 \pm 2.4$ & $14.6 \pm 2$ & $14.7 \pm 2.2$ & $15.0 \pm 2.1$ & $<0.001$ \\
\hline $\begin{array}{c}\text { BMI } \\
\left(\mathrm{kg} / \mathrm{m}^{2}\right)\end{array}$ & $22.4 \pm 4.5$ & $24.3 \pm 5.1$ & $26.6 \pm 6.3$ & $30.7 \pm 6.8$ & $<0.001$ \\
\hline $\begin{array}{l}\text { WC } \\
(\mathrm{cm})\end{array}$ & $67.0 \pm 10.4$ & $72.7 \pm 11.7$ & $76.6 \pm 13.3$ & $86.2 \pm 16.0$ & $<0.001$ \\
\hline $\begin{array}{c}\text { FBS } \\
(\mathrm{mmol} / \mathrm{l})\end{array}$ & $5.0 \pm 0.4$ & $5.1 \pm 0.5$ & $5.1 \pm 0.4$ & $5.2 \pm 0.5$ & $<0.01$ \\
\hline $\begin{array}{c}\text { HDL } \\
(\mathrm{mmol} / \mathrm{l})\end{array}$ & $1.2 \pm 0.3$ & $1.2 \pm 0.3$ & $1.1 \pm 0.3$ & $1.1 \pm 0.2$ & $<0.001$ \\
\hline $\begin{array}{c}\text { SBP } \\
(\mathrm{mmHg})\end{array}$ & $118.1 \pm 9.9$ & $120.9 \pm 10.4$ & $122.4 \pm 12.0$ & $126.4 \pm 11.5$ & $5<0.001$ \\
\hline $\begin{array}{c}\text { DBP } \\
(\mathrm{mmHg})\end{array}$ & $79.1 \pm 7.7$ & $80.6 \pm 8.1$ & $81.5 \pm 8.8$ & $83.7 \pm 8.3$ & $<0.001$ \\
\hline TG-Ln & $-0.5 \pm 0.5$ & $-0.4 \pm 0.5$ & $-0.3 \pm 0.4$ & $-0.2 \pm 0.5$ & $<0.001$ \\
\hline
\end{tabular}

$\mathrm{Ln}=$ transformed to $\log$.

Table 2. Pearson's correlation coefficients for each component of MS with UA concentration $(\mathrm{mg} / \mathrm{dl})(\mathrm{n}=742)$.

\begin{tabular}{ccr}
\hline & Pearson's correlation (r) & p-value \\
\hline WC & 0.545 & $<0.001$ \\
SBP & 0.303 & $<0.001$ \\
DBP & 0.171 & $<0.001$ \\
HDL & -0.316 & $<0.001$ \\
FBS & 0.199 & $<0.001$ \\
TG (Log-transformed) & 0.316 & $<0.001$ \\
\hline
\end{tabular}


Table 3. Risk of MS according to UA concentration $(n=742)$.

\begin{tabular}{cccc}
\hline \multicolumn{3}{c}{ MS } \\
\hline Covariates & $\mathrm{n}$ & OR $(95 \% \mathrm{CI})$ & $\mathrm{p}$-value \\
\hline Gender & & & \\
Male & 303 & Reference 1.0 & \\
Female & 439 & $0.4(0.2-0.5)$ & $<0.001$ \\
UA (quartiles) & & & \\
$1^{\text {st }}$ & 190 & Reference 1.0 & \\
$2^{\text {nd }}$ & 178 & $2.3(0.9-5.5)$ & NS $(0.06)$ \\
$3^{\text {rd }}$ & 191 & $2.9(1.2-6.7)$ & $<0.01$ \\
$4^{\text {th }}$ & 183 & $8.9(4.0-19.6)$ & $<0.001$ \\
\hline
\end{tabular}

$\mathrm{OR}=$ odd ratio $; \mathrm{CI}=$ confidence interval $; \mathrm{NS}=$ non-significant.

quartiles. Age-adjusted binary logistic regression was applied. The risk of MS increased with increased concentration of UA.

Figures 1 and $\mathbf{2}$ show that the level of UA increased in proportion to the number of MS parameters present, both in males and females.

\section{DISCUSSION}

In this study, it was found that there was a significant association of UA with MS. It was observed that serum UA was higher in malesthan females. This result supports the universal fact that estrogen promotes the excretion of UA [1,2].

According to this study's findings, serum UA was more significantly correlated with WC for males (both normal, $\mathrm{r}=0.562, \mathrm{p}<0.001$ and obese, $\mathrm{r}=0.661, \mathrm{p}<$ 0.001 ) and for females (both normal, $r=-0.02, p>0.05$ and obese, $r=0.294, p<0.001$ ), which has been shown in other studies $[3,4]$. This may explain the fact that abdominal fatness is likely to be the basis for metabolic abnormality which may give rise to insulin resistance and may be a predictor for increased cluster of risk factors as the age increases [5].

The parameters: FBS, TG and hypertension were less significantlywith $\mathrm{WC},(\mathrm{p}<0.001)$. When the participants were separated as normal and obese, it was observed that there was an increase in the correlation of UA with glucose in obese males $(r=0.334, p<0.001)$. For females, glucose was insignificant(for normal $r=0.02, p>0.05$ and for obese, $r=0.024, p>0.05$ ). This might be due to dietary and life style reasons. For the former (males), UA may have a pathogenic role for the development of glucose intolerance or insulin resistance. Several mechanisms are well explained for the relationship of insulin resistance and hyperuricemia [6]. Studies revealed that insulin resistance (IR) is inversely related to 24-hour

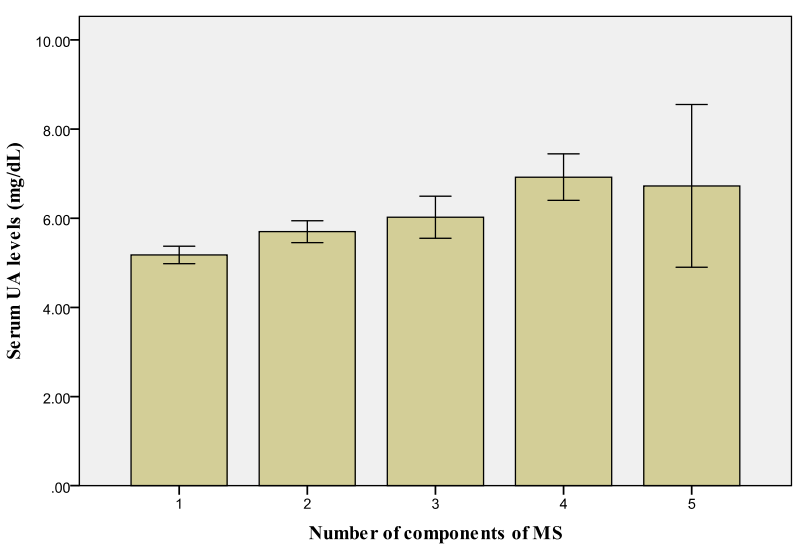

SBP and DBP combined in this figure

Figure 1. US level, according to the number if MS components present among make Kuwaiti adolescents.

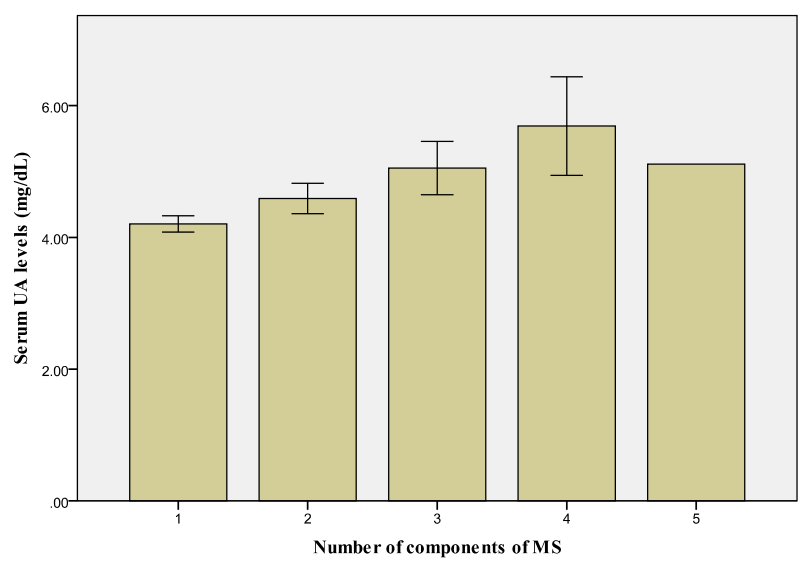

$\mathrm{SBP}$ and DBP combined in this figure

Figure 2. UA level, according to the number of MS components present among female Kuwaiti adolescents.

urinary UA clearance $[7,8]$. Therefore, one mechanism linking hyperinsulinemia (a consequence of IR) with hyperuricemia may be explained by a decreased renal excretion of UA. In fact, insulin can enhance renal tubular sodium re-absorption in humans. Moreover, insulin receptors found in different tubular segments. Whatever the site of the tubular effects of insulin, possible mechanisms include direct stimulation of tubular ion exchange or acceleration of cellular metabolism [9]. Therefore, insulin can modify the handling of UA by the kidney, thus leading to hyperuricemia.

Although, hyperuricemia is well recognized as a risk factor for atherosclerotic diseases such as myocardial infarction [10] and stroke [11], the independence of this association from other risk factors has remained controversial. This is mostly because serum UA is associated with other risk factors, such as hypertension [12] and dyslipidemia [13].

Experimental evidence suggests that increased level of serum UA has a pathogenic role in hypertension, medi- 
ated by several mechanisms such as inflammation and vascular smooth muscle proliferation in the renal microcirculation, endothelial dysfunction, and activation of the renin-angiotensin system $[14,16]$. Recently, a possible association between UA with hypertension has been assessed in a Chinese population, but not thoroughly $[18,19]$.

UA concentrations are highly correlated with renal function, obesity, and metabolic abnormalities. The causative role of UA in hypertension is still a matter of debate. For example, decreased renal blood flow [20] and impaired tubular secretion of UA [21] have been associated with hyperuricemia in hypertensive patients. In overweight and obese subjects, abdominal obesity is associated with high blood pressure via hyperinsulinemia or insulin resistance [7]. Studies has shown that the association between hyperuricemia and hypertension was partly mediated by abdominal obesity [22].

Hypertriglycemia was significant in this study among both genders $(p<0.05)$. HDL was found to be low in this study. The low concentration of HDL in MS patients have been reported in many studies, which confirms that there is an increased risk of developing cardiovascular diseases gradually and in their latter stages of life. However, one study showed that low concentration of HDL were no longer significantly associated with concentration of UA.

Therefore, in order to prevent the progression of MS, it is suggested to initially intervene by reducing the abdominal fatness by physical activity, diet and treatment of the various risk factors, such as hypertension, hyperglycemia and hypertriglycemia, so as to avoid the progression of the development of cardiovascular disease and increase the life span of human beings.

\section{CONCLUSION}

The level of uric acid among the adolescent was high and it was significantly associated with MS and gender. Dietary interventions are necessary to reduce UA and the parameters of MS among Kuwaiti adolescents.

\section{REFERENCES}

[1] Fang, J., Jing, M.D. and Alderman, M.H. (2000) Serum uric acid and morality: The NHANESI epidemiologic follow-up study, 1971-1992. National and Nutrition EXamination Survey, JAMA, 283, 2404-2410. doi:10.1001/jama.283.18.2404

[2] Bos, M.J., Koudstaell, P.J., Hofman, A., Witteman, J.C. and Breteler, M.M. (2006) Uric acid is a risk factor for myocardial infarction and stroke: The Rotterdam study. Stroke, 37, 1503-1507. doi:10.1161/01.STR.0000221716.55088.d4

[3] Strasak, A., Ruttmann, E., Brant, L., Kelleher, C., Klenk,
J., Concin, H., Diem, G., Pfeiffer, K., Ulmer, H. and VHM PP Study Group (2008) Serum uric acid and risk of cardiovascular mortality: A prospective long-term study of 83,683 Austrian men. Clinical Chemstry, 54, 273-284. doi:10.1373/clinchem.2007.094425

[4] Lippi, G., Montagana, M., Franhini, M., Favaloro, E.J. and Targher, G. (2008) The paradoxical relationships between serum uric acid and cardiovascular disease. Clinica Chemica Acta, 392, 1-7. doi:10.1016/j.cca.2008.02.024

[5] Ford, E.S., Li, C., Cook, S. and Choi, H.K. (2007) Serum concentration of uric acid and the metabolic syndrome among US children and adolescents. Circulation, 115, 2526-2532.

doi:10.1161/CIRCULATIONAHA.106.657627

[6] Nagahama, K., Iseki, K., Ihoue, T., Touma, T., Ikemiya, Y. and Takishita, S. (2004) Hyperuricemia and cardiovascular risk factor clustering in a screened cohort in Okinawa, Japan. Hypertension Research, 27, 227-233. doi:10.1291/hypres.27.227

[7] Banora, E., Kiechl, S., Willeit, J., Oberhollenzer, F., Egger, G., Bonadonna, R.C. and Muggo, M. (2003) Bruneck study. Carotid atherosclerosis and coronary heart disease in themetabolic syndrome: Prospective data from the Bruneck study. Diabetes Care, 26, 1251-1257. doi:10.2337/diacare.26.4.1251

[8] Johnson, R.J., Kang, D.H., Feig, D., Kivilighn, S., Kanellis, J., Watanabe, S., Tuttle, K.R., Rodriguez-Iturbe, B., Herrera-Acosta, J. and Mazzali, M. (2003) Is there a pathogenetic role for uric acid in hypertension and cardiovascular and renal disease? Hypertension, 41, 1183-1190. doi:10.1161/01.HYP.0000069700.62727.C5

[9] Kanellis, J. and Kang, D.H. (2005). Uric acid as a mediator of endothelial dysfunction, inflammation and vascular disease. Seminars in Neurology, 25, 39-42.

[10] Ishizaka, N., Ishizaka, Y., Toda, E.-I., Nagai, R. and Yamakado, M. (2005) Association between serum uric acid, metabolic syndrome, and carotid atherosclerosis in Japanese individuals. Atherosclerosis, Thrombosis and Vascular Biology, 25, 1038-1044. doi:10.1161/01.ATV.0000161274.87407.26

[11] Ishizaka, N., Ishizaka, Y., Toda, E., Hashimoto, H., Nagai, R. and Yamakado, M. (2007) Higher uric acid is associated with increased arterial stiffness in Japanese individuals. Atherosclerosis, 192, 131-137. doi:10.1016/j.atherosclerosis.2006.04.016

[12] Kawamoto, R., Tomita, H., Oka, Y. and Ohtsuka, N. (2006) Relationship between uric acid concentration, metabolic syndrome, and carotid atherosclerosis. Internal Medicine, 45, 605-614. doi:10.2169/internalmedicine.45.1661

[13] Iribarren, C., Folsom, A.R., Eckfelt, J.H., McGovern, P.C. and Nieto, F.J. (1996) Correlates of uric acid and its association with asymptomatic carotid atherosclerosis: The ARIC study. Atherosclerosis risk in communities. Annals of Epidemiology, 6, 331-340. doi:10.1016/S1047-2797(96)00052-X

[14] Berenson, G.S., Srinivasan, S.R., Bao, W., Newman, W.P. III, Tracy, R.E. and Wattigney, W.A. (1998) Association between multiple cardiovascular risk factors and atherosclerosis in children and young adults. The Bogalusa 
heart study. New England Journal of Medicine, 338, 16501656. doi:10.1056/NEJM199806043382302

[15] Solymoss, B.C., Bourassa, M.G., Campeau, L., Sniderman, A., Marcil, M., Lesprance, J., Levesque, S. and Varga, S. (2004) Effect of increasing metabolic syndrome score on atherosclerotic risk profile and coronary artery disease angiographic severity. American Journal of Cardiology, 93, 159-164. doi:10.1016/j.amjcard.2003.09.032

[16] Desai, M.Y., Santos, R.D., Dalal, D., Carvalho, J.A., Martin, D.R., Flynn, J.A., Nasir, K., and Blumenthal, R.S. (2005) Relation of serum uric with metabolic risk factors in asymptomatic middle-aged Brazilian men. American Journal of Cardiology, 95, 865-868. doi:10.1016/j.amjcard.2004.12.013

[17] Al-Isa, A.N., Campbell, J., Desapriya, E. and Wijesinghe, N. (2010) Factors associated with overweight and obesity among Kuwaiti elementary male school children aged 6 10 years. International Journal of Pediatrics, 2010, 1-7. doi: $10.1155 / 2010 / 459261$

[18] Chen, J.H., Chuang, S.Y., Chen, H.J., Yeh, W.T. and Pan, W.H. (2009) Serum uric acid level as an independent risk factor for all cause, cardiovascular, and ischemic stroke mortality: A Chinese cohort study. Arthritis Rheum, 61, 225-232. doi:10.1002/art.24164

[19] Messererli, F.H., Frohlich, E.D., Dreslinski, G.R., Suarez, D.H. and Aristimuno, G.G. (1980) Serum uric acid in essential hypertension: An indicator of renal vascular involvement. Annals of Internal Medicine, 93, 817-821. doi:10.7326/0003-4819-93-6-817

[20] Cappucio, F.P., Strazzulo, P., Ferinaro, E. and Trevisan, M. (1993) Uric acid metabolism and tubular sodium handling. JAMA, 270, 354-359. doi:10.1001/jama.1993.03510030078038

[21] Zhang, W., Sun, K., Ying, Y., Zhang, H., Hu, F.B. and Hui, R. (2009) Plasma uric acid and hypertension in a Chinese community: Prospective study and metaanalysis. Clinical Chemistry, 55, 2026-2034. doi:10.1373/clinchem.2009.124891

[22] Hayashi, T., Boyko, E.J., Leonetti, D.L., McNeely, M.J., Newell-Morris, L., Khan, S.E. and Fujimoto, W.Y. (2004) Vesceral adiposity in as independent predictor of incident hypertention in Japanese Americans. Annals of Internal Medicine, 140, 992-1000. doi:10.7326/0003-4819-140-12-200406150-00008 